\title{
Electrochemical Properties and Challenges of Type II Silicon Clathrate Anode in Sodium Ion Batteries
}

\author{
Xuemin Li, ${ }^{1}$ K. Xerxes Steirer, ${ }^{2}$ Lakshmi Krishna, ${ }^{2}$ Chuanxiao Xiao, ${ }^{1}$ Kae Fink, ${ }^{1, *}$ \\ and Shriram Santhanagopalan 1 1,z
}

${ }^{I}$ National Renewable Energy Laboratory (NREL), Golden, Colorado 80401, USA

${ }^{2}$ Department of Physics, Colorado School of Mines, Golden, Colorado 80401, USA

\begin{abstract}
The development of advanced anodes for low-cost room temperature sodium-ion batteries (SIBs) with high cycling stability is of great significance. Silicon clathrates are promising intercalation anodes due to their cage-like frameworks. It is predicted that the open cages can easily accommodate alkali ions with negligible volume changes. However, the complicated surface structure and chemical reactions make it challenging to understand the electrochemical performance of clathrate anodes in SIBs. In this paper, we evaluated the performance of type II clathrate anodes in SIBs. A slightly elevated testing temperature $\left(45^{\circ} \mathrm{C}\right)$ is shown to improve the cell capacity and rate performance due to the improved ionic conductivity. However, side reactions on the solid electrolyte interface (SEI) and loss of active material during the first sodiation process contribute to the low Coulombic efficiency during the first cycle. Analysis is supported by electrode morphology, elemental mapping, and X-ray photoelectron spectroscopy (XPS) on the clathrate electrodes at different electrochemical states. $\mathrm{Na}^{+}$ion transport behavior between clathrate cages and surface in terms of migration barriers was also computed to explain the positive effect of higher cell testing temperature, and the low Coulombic efficiency of the first cycle.

(C) The Author(s) 2019. Published by ECS. This is an open access article distributed under the terms of the Creative Commons Attribution Non-Commercial No Derivatives 4.0 License (CC BY-NC-ND, http://creativecommons.org/licenses/by-nc-nd/4.0/), which permits non-commercial reuse, distribution, and reproduction in any medium, provided the original work is not changed in any way and is properly cited. For permission for commercial reuse, please email: oa @ electrochem.org. [DOI: 10.1149/2.1201913jes]

(c)) BY-NC-ND
\end{abstract}

Manuscript submitted July 25, 2019; revised manuscript received August 18, 2019. Published September 10, 2019. This was Paper 1120 presented at the Dallas, Texas, Meeting of the Society, May 26-May 30, 2019.

Rechargeable lithium (Li)-ion batteries (LIBs) have been widely used in portable electronics and large-scale grid energy storage. However, high cost of raw materials such as $\mathrm{Li}$, cobalt, and nickel ${ }^{1}$ incentivize recycling and reusing spent battery electrode materials. ${ }^{2}$ Another strategy to alleviate this problem is to investigate alternative battery technologies beyond LIBs such as sodium-ion batteries (SIBs). Ambient temperature SIBs have raised much attention recently due to the abundant resources and low costs of sodium metal. ${ }^{1,3,4}$ In addition, $\mathrm{Na}$ shares many similar chemical properties with $\mathrm{Li}$ as alkali metals. ${ }^{5}$ However, the main limitation of SIB development and application is the anode active material because graphite, the commercial anode in LIBs, provides much lower energy density in SIBs due to the large radius of the sodium ions $\left(\mathrm{Na}^{+}\right)$. Finding new anode materials for SIBs that can accommodate $\mathrm{Na}^{+}$is important for the development of high energy density rechargeable batteries.

Silicon $(\mathrm{Si})$ clathrates are polymorphs of $\mathrm{Si}$ with cage-like frameworks that can encapsulate various guest atoms or molecules. ${ }^{6}$ In contrast to the normal face-centered cubic (fcc) $\mathrm{Si}$ which suffers from huge volume fluctuation during alkali ion insertion and extraction, ${ }^{7,8}$ the open cage structures of Si clathrates, in theory, can easily accommodate alkali ions with negligible volume changes. ${ }^{9,10}$ Type I and type II Si clathrate structures are the most investigated clathrate materials for LIBs and SIBs. The type I Si clathrate has the general formula of $\mathrm{M}_{\mathrm{x}} \mathrm{Si}_{46}(0<\mathrm{x}<8)$ where $\mathrm{M}$ denotes the guest atoms such as $\mathrm{Na}$. The type I Si clathrate is composed of two pentagonal dodecahedron cages and six tetrakaidecahedra per unit cell. The type II Si clathrate in the form of $\mathrm{M}_{\mathrm{x}} \mathrm{Si}_{136}(0<\mathrm{x}<24)$ is made of 16 pentagonal dodecahedra and 8 hexakaidecahedra per unit cell. ${ }^{11,12}$

Experimental $^{11,13-16}$ and theoretical ${ }^{11,17-19}$ studies of type $\mathrm{I}^{11,13,14,16-18,20}$ and type $\mathrm{II}^{11,15,19} \mathrm{Si}$ clathrates as anode materials for LIBs have been reported since 2012. For the first time, Langer et al. showed that lithium ions $\left(\mathrm{Li}^{+}\right)$can successfully be inserted into type II Si clathrates, and the clathrate structure can be preserved during $\mathrm{Li}^{+}$ insertion. ${ }^{15}$ Wagner et al. studied the electrochemical performance of a mixture of type I and type II clathrates in LIBs. ${ }^{11}$ They reported low Coulombic efficiency (CE) $(\sim 50 \%)$ due to phase transformation, volume changes, and possibly SEI formation. The specific capacities

\footnotetext{
*Electrochemical Society Student Member.
}

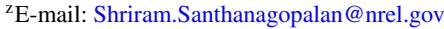

were found to decrease significantly from $1213 \mathrm{mAh} / \mathrm{g}$ at the $1^{\text {st }}$ cycle to $171 \mathrm{mAh} / \mathrm{g}$ at the $5^{\text {th }}$ cycle. Later, Li et al. presented the electrochemical performance of the type $\mathrm{I} \mathrm{Ba}_{8} \mathrm{Al}_{\mathrm{y}} \mathrm{Si}_{46-\mathrm{y}}$ clathrate as an anode for LIBs. They applied X-ray diffraction and nuclear magnetic resonance to confirm that no discernible structural or volume changes occurred after electrochemical insertion of $44 \mathrm{Li}^{+}$into the clathrate structure. They also suggested that the electrochemical reactions were single-phase reactions. ${ }^{20}$ Zhao et al. investigated the impact of surface defects via ballmilling and acid/base treatment on the electrochemical performance of a $\mathrm{Ba}_{8} \mathrm{Al}_{16} \mathrm{Si}_{30}$ type I Si clathrate. They concluded that amorphous surface layers were preferred for $\mathrm{Li}^{+}$insertion. Chan et al. extended the cell life and showed that the empty $\mathrm{Si}_{46}$ electrodes exhibit long-term cycling stability with the specific discharging capacity of $\sim 550 \mathrm{mAh} / \mathrm{g}$ after 1000 cycles, but did not show the CEs and capacities of the first four cycles. ${ }^{14,17}$

Research on Si clathrate anodes in SIBs is relatively scarce compared with that in LIBs. The possibility of using open framework allotropes of $\mathrm{Si}$ as potential anode materials for LIBs and SIBs was evaluated by $\mathrm{He}$ et al., ${ }^{21}$ Arrieta et al., ${ }^{9}$ and Marzouk et al. ${ }^{22}$ using computational methods. It is predicted that $\mathrm{Na}_{\mathrm{x}} \mathrm{Si}$ forms a solid solution with minimal volume changes. ${ }^{9,21}$ Therefore, the major advantage of allotropes is the stable capacity during charge-discharge cycles. ${ }^{22}$ However, Na-ion diffusion is predicted to be insufficiently fast for $\mathrm{Na}-$ ion intake. ${ }^{9} \mathrm{Na}^{+}$diffusion was investigated by Slingsby through type II Si clathrates by means of biased molecular dynamics and kinetic Monte Carlo simulations. ${ }^{12}$ They showed that $\mathrm{Na}^{+}$ions could not be extracted from type I clathrates by heating under vacuum, while $\mathrm{Na}^{+}$ de-intercalation is feasible in type II clathrates. ${ }^{12}$

To the best of our knowledge, investigation of the type II clathrate materials as anodes for room-temperature SIBs has not been conducted in the literature. Hence, we studied the type II clathrate anode performance in SIBs, improved the capacity by increasing the cycling temperature, and explained the low CE of the first cycle. This report will be a valuable guidance for future clathrate developments in SIBs.

\section{Experimental}

Synthesis of type II clathrates.-The type II clathrates were synthesized using the decomposition reaction of $\mathrm{NaSi}$ to form type II clathrates following the procedure of the previous research. ${ }^{23}$ 
Briefly, NaSi was synthesized by heating $\mathrm{NaH}$ (95\%, Aldrich) and Si $(99.9999 \%$, Alfa Aesar) at the molar ratio of 1.6: 1 in an alumina crucible for $48 \mathrm{~h}$ at $395^{\circ} \mathrm{C}$ under an argon atmosphere. Then, to thermally decompose $\mathrm{NaSi}$ into the clathrate, the NaSi sample was heated at $370^{\circ} \mathrm{C}$ under vacuum in a tube furnace in conjunction with a watercooled plate (at $25^{\circ} \mathrm{C}$ ) inside the reaction chamber. Finally, to reduce the $\mathrm{Na}^{+}$occupancy, the product was sonicated for $15 \mathrm{~min}$ in acid (3 vol\% hydrofluoric acid aqueous solution).

Characterization.-The clathrate powders were characterized using scanning electron microscopy (SEM) and energy dispersive X-ray spectroscopy (EDS) on a FEI Nova 630 field emission SEM with a Pegasus system from an EDAX detector with a Hikari camera. The accelerating voltage was set to $15 \mathrm{kV}$. Sample powders were spread on an aluminum stub using a double-sided carbon tape. To confirm the phase purity of the synthesized clathrate powders, X-ray diffraction (XRD) characterizations were conducted on a Rigaku DMax X-ray diffractometer using $\mathrm{Cu} \mathrm{K} \alpha$ radiation $(\lambda=0.15405 \mathrm{~nm})$, scintillation counter detector, $10 \mathrm{~mm}$ divergent height limiter slit, and $0.8 \mathrm{~mm}$ receiving slit. The XRD samples were prepared by spreading the sample powders on a glass holder using transparent double-sided tape.

Clathrate electrodes were prepared by first making the slurry. The clathrate powder $(70 \mathrm{wt} \%)$ and conductive carbon black $(25 \mathrm{wt} \%)$ were blended manually in a mortar. Then carboxymethyl cellulose (CMC) binder (5 wt \%) dissolved in deionized water was added into the above mixture. After stirring overnight, the slurry was coated using a doctor blade onto the copper $(\mathrm{Cu})$ current collector. After that, the dried electrodes were cut into small disks with a diameter of 9/16 inch. The mass loading of clathrate was $\sim 1.0 \mathrm{mg} / \mathrm{cm}^{2}$. Na metal foil was prepared by rolling a piece of Na cube (Sigma-Aldrich, $99.9 \%$ trace metals basis) into Na foil with thickness of $\sim 0.5 \mathrm{~mm}$. Coin cells (2032) were assembled using clathrate (working electrode, diameter of 9/16 inch), Na metal (counter electrode, diameter of 5/8 inch), Whatman glass fiber (Grade GF/F, with thickness of 420 micrometer, diameter of $17 \mathrm{~mm}$ ) as the separator, and electrolyte of $1.0 \mathrm{M} \mathrm{NaPF}_{6}$ dissolved in ethylene carbonate (EC)/diethyl carbonate (DEC) (volume ratio between $\mathrm{EC}$ and $\mathrm{DEC}=1$ ). Coin cells were tested at room temperature and $45^{\circ} \mathrm{C}$ across a voltage window of $0.01 \mathrm{~V}-2.0 \mathrm{~V}$. The testing current was set to $\mathrm{C} / 20$ for the first two cycles; $\mathrm{C} / 10$ for the following 15 cycles; then $\mathrm{C} / 5, \mathrm{C} / 2$, and $1 \mathrm{C}$ for 10 cycles for each current setting; and finally, $\mathrm{C} / 20$ for the last cycle $(1 \mathrm{C}=168 \mathrm{mAh} / \mathrm{g})$.

Cyclic voltammetry (CV) and electrochemical impedance spectroscopy (EIS) measurements were conducted using a potentiostat (Princeton Applied Research, Versastat 4) at room temperature. The $\mathrm{CV}$ scan speed was set to $0.1 \mathrm{mV} / \mathrm{s}$ across the voltage window of $0.01 \mathrm{~V}-1.5 \mathrm{~V}$. For EIS, the amplitude was $10 \mathrm{mV}$ and the frequency ranged from $100 \mathrm{kHz}$ to $0.1 \mathrm{~Hz}$. In addition, the cell impedance spectra at different cell voltages were obtained by measuring the $\mathrm{AC}$ impedance after every 60-minute constant current discharge step at the rate of $\mathrm{C} / 10$ until the cell voltage reached $0.01 \mathrm{~V}$.

To corroborate the electrochemical reaction mechanisms of clathrate anodes, SEM and EDS mapping were obtained on the fresh clathrate electrode, the electrode after the initial discharge from OCV to $0.01 \mathrm{~V}$ (sodiated), and the cycled electrodes (desodiated). These electrodes extracted from coin cells were rinsed using DEC solvent to get rid of electrolyte salts on the surface before the SEM and EDS characterizations. To study the bulk phase change after the electrochemical cycling, XRD characterizations were measured on the cycled clathrate electrode to compare with that of the fresh electrode and synthesized clathrate powders. The same cleaning method was used for XRD sample preparation. In these characterization experiments, the cycled clathrate anodes were all retrieved from coin cells cycled at room-temperature, unless specified.

XPS was performed on a HiPP-III Scienta-Omicron photoelectron spectrometer operating in swift mode. Pass energy and analyzer slit width were $500 \mathrm{eV}$ and $4 \mathrm{~mm}$ for surveys, and $200 \mathrm{eV}$ and $1.5 \mathrm{~mm}$ for core level scans. An $800 \mu \mathrm{m}$ aperture was fixed on the analyzer entrance. Monochromatic AlK $\alpha \mathrm{X}$-rays were used to generate the photoelectron signal. A single point calibration was performed using $\mathrm{Au}$ $4 \mathrm{f}_{7 / 2}$ at $83.98 \mathrm{eV}$. Analysis was performed using CASA XPS.

\section{Results and Discussion}

Electrochemical performance.-XRD patterns, electrode morphology (SEM images) and elemental (EDS) results of the synthesized type II clathrate particles are shown in Figure $1 \mathrm{~A}$ and Figure $1 \mathrm{~B}$, respectively. The XRD broad background peak at the range of $10^{\circ}-30^{\circ}$ is from the glass substrate. XRD patterns of the synthesized clathrate particles (black line) match the standard patterns of $\mathrm{NaSi}_{136}$ (type II clathrate, magenta line), with an additional peak at $28.3^{\circ}$ which is ascribed to the fcc $\mathrm{Si}$, indicating the production of crystalline type II clathrates with a small amount of impurity. ${ }^{23}$ Based on the Rietvel refinement of XRD patterns conducted with the GSAS suite, the weight percent of the impurity is $\sim 2.7 \mathrm{wt} \%$. The clathrate crystal size is estimated to be $\sim 30 \mathrm{~nm}$ according to the Scherrer equation, which correlates crystalline domains with peak full width at half maximum. The as-synthesized clathrate powders are mainly agglomerations of small particles, as shown in Figure 1B. EDS results of the clathrate powders are listed in Figure 1B. The atomic ratio between $\mathrm{Na}$ and $\mathrm{Si}$ is $4.5: 35.3$, with the stoichiometric form of $\mathrm{Na}_{17.8} \mathrm{Si}_{136}$ after eliminating $2.7 \mathrm{wt} \%$ of fcc $\mathrm{Si}$ impurity, which falls in the range of $\mathrm{M}_{\mathrm{x}} \mathrm{Si}_{136}$ $(0<\mathrm{x}<24)$ and is higher than that of $\mathrm{NaSi}_{136}$, indicating that $\mathrm{Na}^{+}$ions in the synthesized type II clathrates were not fully extracted, but the crystalline structure was preserved the same as that of $\mathrm{NaSi}_{136}$.

The electrochemical properties of the type II clathrate were evaluated in SIBs including CV, cell cycling performance at different current rates, voltage profiles, and derivative voltage $(\mathrm{dQ} / \mathrm{dV})$
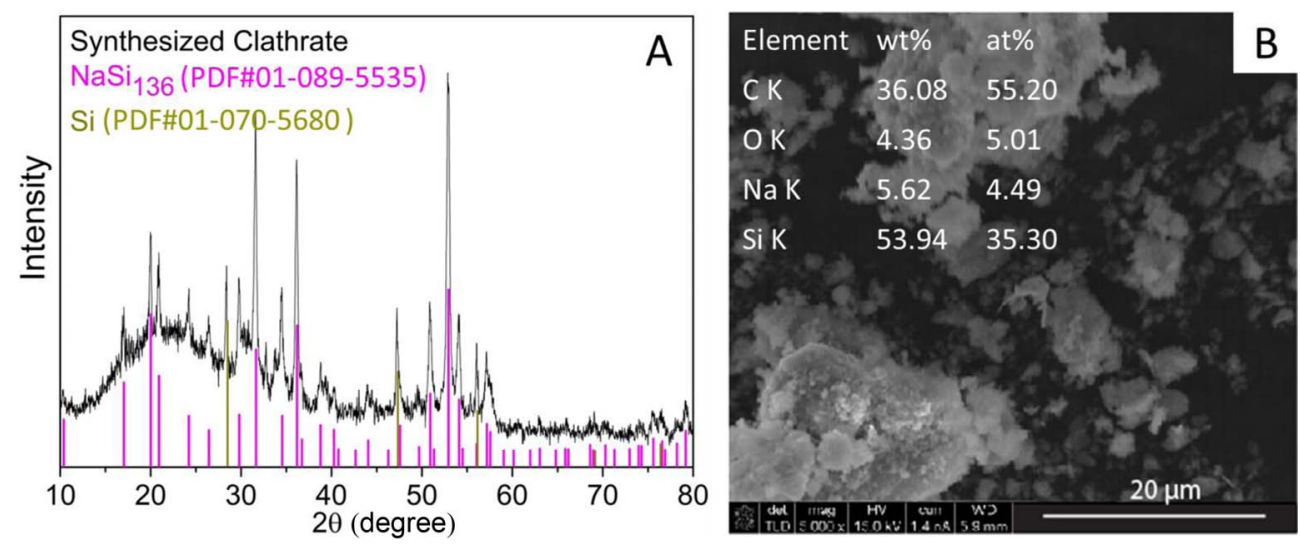

Figure 1. Structural and morphology characterizations of the as-synthesized type II clathrate powders. (A) XRD patterns of the synthesized particles (black) and the standard patterns of fcc $\mathrm{Si}$ (yellow) and $\mathrm{NaSi}_{136}$ (magenta) for comparison. (B) SEM image with the elemental analysis from EDS as the inset. 

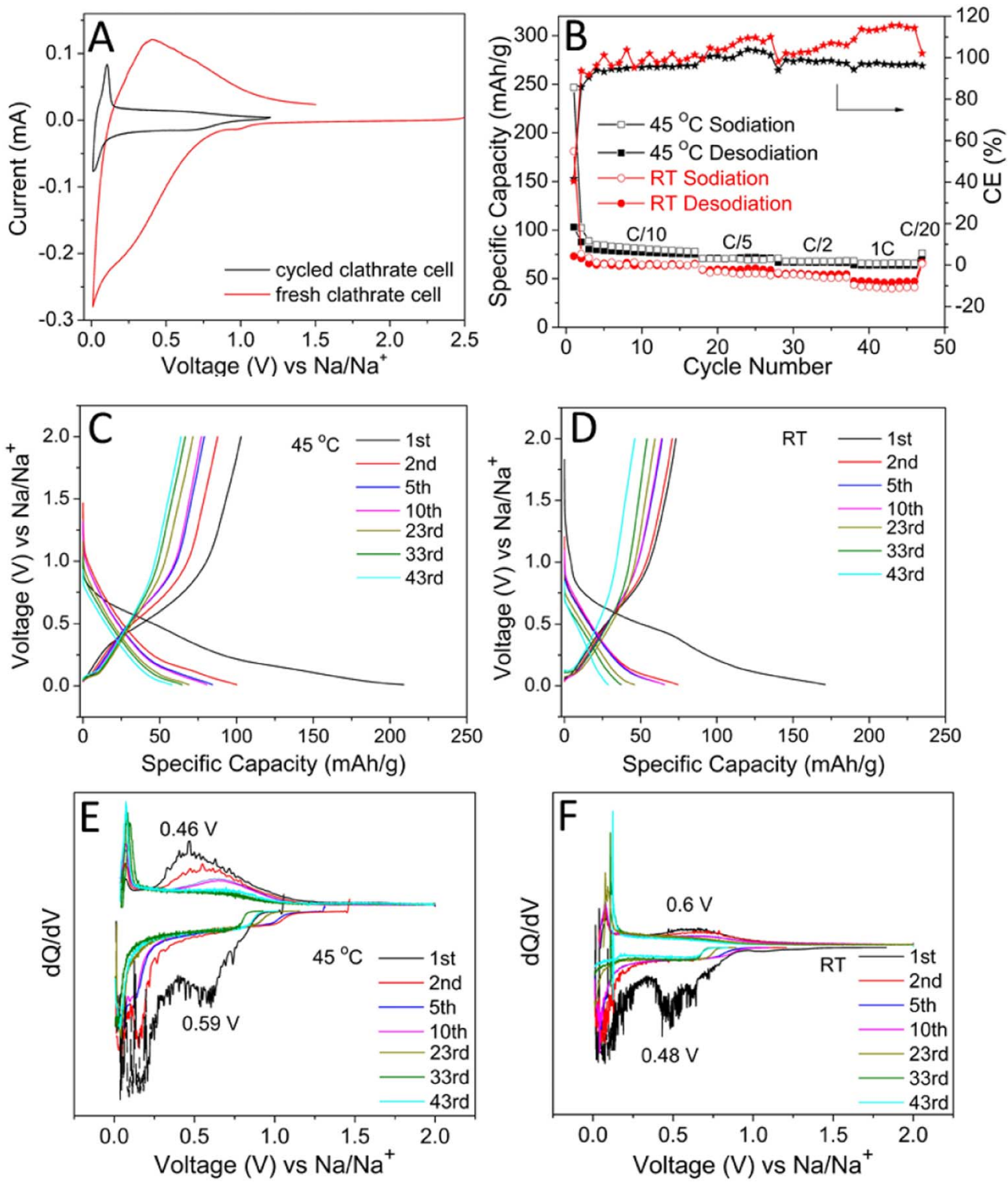

Figure 2. Clathrate anode electrochemical results. (A) CV spectra of the fresh (red) and cycled (black) coin cells measured at room temperature. (B) Galvanostatic electrochemical cycling performance of the clathrate anodes vs. Na tested at room temperature (red) and $45^{\circ} \mathrm{C}$ (black). (C) and (D) Voltage profiles at different cycle numbers for cells that were cycled at $45^{\circ} \mathrm{C}$ and room temperature, respectively. (E) and (F) Differential capacity plots at different cycle numbers at $45^{\circ} \mathrm{C}$ and room temperature, respectively.

profiles as shown in Figures 2A through 2F. Figure 2A shows the $\mathrm{CV}$ profiles of the fresh and cycled (room temperature) clathrate anodes to understand the electrochemical property changes after cycling. The distinct oxidation peak at $\sim 0.42 \mathrm{~V}$ in the fresh anode (red line) became almost unobservable after cycling (black line) while leaving the main oxidation peak at $0.1 \mathrm{~V}$ attributed to the reaction of $\mathrm{Na}^{+}$with carbon black. ${ }^{13}$ Therefore, it is predicted that the $\mathrm{Na}^{+}$de-intercalation reaction in the clathrate at $0.42 \mathrm{~V}^{13}$ mainly contributes to the cell capacity, and its intensity decreases during cell decay. The CV profile changes can be supported by the following voltage profile and $\mathrm{dQ} / \mathrm{dV}$ analysis.

The theoretical capacity of the type II clathrate $\mathrm{Si}_{136}$ to form $\mathrm{Na}_{24} \mathrm{Si}_{136}$ is $168 \mathrm{mAh} / \mathrm{g}$. The impurity of fcc crystalline $\mathrm{Si}(2.7 \mathrm{wt} \%)$ can theoretically contribute at most $25.7 \mathrm{mAh} / \mathrm{g}$. The as-prepared clathrate sample showed an open circuit voltage of $\sim 2 \mathrm{~V}$. Cell cycling was started from discharging to the cutoff voltage of $0.01 \mathrm{~V}$ $\left(\mathrm{Na}^{+}\right.$intercalation or sodiation). The first discharge capacity was $181.2 \mathrm{mAh} / \mathrm{g}$ using the current of $\mathrm{C} / 20$ at room temperature, while the first charge capacity $\left(\mathrm{Na}^{+}\right.$deintercalation or desodiation) was
$73.2 \mathrm{mAh} / \mathrm{g}$ at the same cycling condition. At $45^{\circ} \mathrm{C}$, these values increased to $246.9 \mathrm{mAh} / \mathrm{g}$ and $102.9 \mathrm{mAh} / \mathrm{g}$, respectively, as shown in Figure $2 \mathrm{~B}$. At both temperatures, the cell capacities were relatively stable, especially for cells tested at $45^{\circ} \mathrm{C}$, confirming that higher temperature can improve the cell capacity and cycling stability. This phenomenon can be partially explained by the improved electrolyte ionic conductivity at elevated temperature $\left(11.00 \mathrm{mS}\right.$ at $\left.45^{\circ} \mathrm{C}\right)$ compared with that at room temperature $(8.55 \mathrm{mS}$, measured on a YSI 3100 conductivity meter). The $\mathrm{CE}$ of the first cycle was low (40.4\% at room temperature and $73.2 \%$ at $45^{\circ} \mathrm{C}$ ), possibly caused by the crystalline fcc Si impurity and SEI side reactions during $\mathrm{Na}^{+}$intercalation. Based on the initial $\mathrm{Na}^{+}$intercalation capacity at room temperature, about $24 \mathrm{Na}^{+}$ions were inserted into each $\mathrm{Na}_{17.8} \mathrm{Si}_{136}$ molecule, indicating that side reactions occurred with excessive $\mathrm{Na}^{+}$, possibly involving $\mathrm{Si}$ clathrate and electrolyte solvents.

Figure 2C and Figure 2D are voltage profiles of the cells tested at different temperatures. The dQ/dV plots (Figure 2E and Figure 2F) derived from the charging/discharging profiles make the plateaus of the voltage profiles more distinct in the form of peaks that represent 

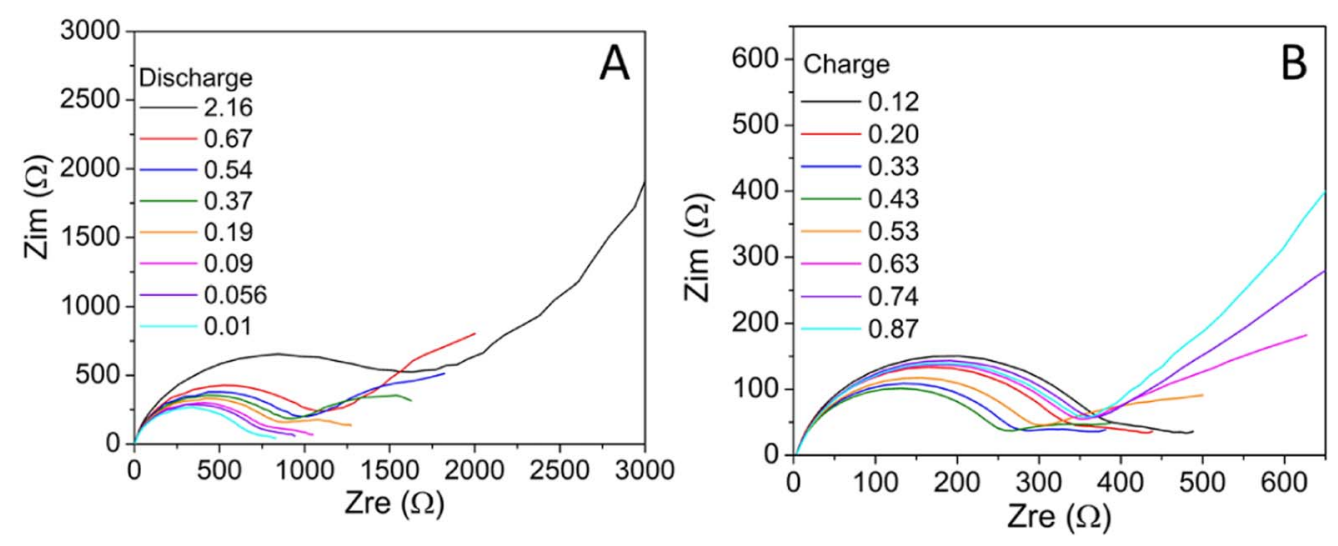

Figure 3. EIS spectra at different voltages for the fresh clathrate anode during (A) discharge (sodiation) and (B) charge (desodiation) processes. The numbers listed in each figure represent the cell voltages (V) where EIS measurements were conducted.

phase changes during the electrochemical reactions. The reduction peak at $0.59 \mathrm{~V}$ for cells at $45^{\circ} \mathrm{C}$ shown in Figure $2 \mathrm{E}$ or $0.48 \mathrm{~V}$ for cells at room temperature shown in Figure $2 \mathrm{~F}$ can be observed during the first discharging step but disappears in the subsequent cycles. Therefore, the phase change during the first sodiation is irreversible, leading to low $\mathrm{CE}$ of the first cycle. The oxidation peak at $0.46 \mathrm{~V}$ for cells at $45^{\circ} \mathrm{C}$ or $0.6 \mathrm{~V}$ for cells at room temperature becomes weaker with more cycling because active material decreases during cycling, which agrees with the $\mathrm{CV}$ results. Comparing the effect of testing temperatures, the cells at $45^{\circ} \mathrm{C}$ show higher oxidation peak intensity than that of the room temperature cells, suggesting that the slightly elevated temperature can improve the deintercalation reaction activity. In addition, the higher oxidation and lower reduction peak positions at room temperature indicate higher cell resistance than $45^{\circ} \mathrm{C}$. In the following characterizations and analysis, the cycled clathrate anodes were all retrieved from room-temperature cycled cells unless specified.

To understand the electrochemical reaction mechanisms, EIS at different voltages during the first full discharge and charge processes were recorded and are shown in Figure 3. Figure 3A includes the impedance spectra at different voltages from open circuit voltage to $0.01 \mathrm{~V}$, and Figure $3 \mathrm{~B}$ shows the impedance spectra from $0.01 \mathrm{~V}$ to $1 \mathrm{~V}$. In Figure $3 \mathrm{~A}$, at voltages higher than $0.5 \mathrm{~V}$, the plots exhibit one depressed semicircle in the high-to-medium frequency regime representing charge transfer impedance and a sloped line at low frequencies relating to the mass diffusion through a semi-infinite medium. The shape of the impedance spectra changed as the voltage gets lower than $0.5 \mathrm{~V}$. A new small semicircle replaced the sloped line. The shape change is related to the surface morphology change during the electrochemical reactions as pointed out in previous literature that the case-to-case variation in the solid phase mass transport in the low frequency can be affected by the electrode morphology and composition. ${ }^{24-27}$ Considering the voltage profile and SEM analysis, the phase change at $\sim 0.5 \mathrm{~V}$ during the first discharge may contribute to the impedance spectra shape change. In general, during the first discharging process, the charge transfer impedance continuously decreases because the sodiated clathrate becomes more conductive compared with the fresh clathrate material. However, the charge transfer impedance change is more complicated during the charging process as shown in Figure 3B. The complicated impedance changes (continuously decreasing $(0.01-$ $0.5 \mathrm{~V})$ first, and then increasing $(>0.5 \mathrm{~V})$ as the cell voltage increases) may be caused by multiple factors, including SEI formation and thickening, $\mathrm{Na}+$ diffusivity at different $\mathrm{Na}+$ concentration, and deintercalation dynamics. The charge transfer resistance values during the cell discharging and charging processes were fit to an equivalent circuit model, and the parameters are included in Table I.

Similar to the discharging process, during charging, the low frequency tail of the spectra recorded at voltages lower than $0.5 \mathrm{~V}$ is close to the real axis, while at voltages higher than $0.5 \mathrm{~V}$, the low frequency tail can be described by Warburg-type impedance. This phenomenon shows that below $0.5 \mathrm{~V}$ the mass diffusion condition deviates from the semi-infinite diffusion and the diffusivity decreases. ${ }^{28}$

Electrode characterization.-Figure 4 includes XRD results of the fresh anode, cycled anode, and as-synthesized clathrate powders. The comparison of XRD patterns were limited to the range of $15^{\circ}-40^{\circ}$ to eliminate the $\mathrm{Cu}$ current collector peaks. The XRD peak positions did not change after cycling. Therefore, the bulk phase of the active material on the electrode did not change during cycling, although it is possible that amorphous byproducts on the surface of clathrate anode formed.

In the following section, SEM and EDS mapping are discussed to understand the initial low $\mathrm{CE}$ and cell capacity decay. Figure 5 includes the SEM images of the fresh electrode (Figure 5A), electrode after the first discharge $(\mathrm{OCV}-0.01 \mathrm{~V}$, Figure $5 \mathrm{~B})$, and after the cycling at room temperature (Figure 5C). After the first discharge and cycling, nanowire/nanorods can be observed in the anode, which may originate from the glass fiber separator contaminants. The atomic ratio between $\mathrm{Na}$ and $\mathrm{Si}$, listed in Table II, gets higher after $\mathrm{Na}^{+}$intercalation into the

Table I. Equivalent circuit model used to fit the EIS results during cell charging and discharging.

\begin{tabular}{|c|c|c|c|c|c|c|}
\hline Equivalent Circuit Model & Discharging voltage (V) & Ro (Ohms) & $\mathrm{R}(\mathrm{Ohms})$ & Charging voltage (V) & Ro (Ohms) & $\mathrm{R}$ (Ohms) \\
\hline & 2.16 & 2.77 & 1322.0 & 0.12 & 3.02 & 384.7 \\
\hline & 0.67 & 2.74 & 1050.0 & 0.20 & 2.93 & 341.6 \\
\hline & 0.54 & 2.80 & 941.1 & 0.33 & 2.89 & 277.4 \\
\hline$-w_{0}$ & 0.37 & 2.85 & 898.0 & 0.43 & 2.98 & 261.0 \\
\hline & 0.19 & 2.88 & 831.2 & 0.53 & 3.20 & 305.4 \\
\hline & 0.09 & 3.09 & 722.6 & 0.63 & 3.47 & 371.7 \\
\hline & 0.056 & 3.10 & 717.0 & 0.74 & 3.49 & 366.6 \\
\hline & 0.01 & 2.96 & 655.0 & 0.87 & 3.50 & 375.7 \\
\hline
\end{tabular}


Table II. Elemental composition from EDS for fresh clathrate, sodiated clathrate after the first discharge from open circuit voltage to $0.01 \mathrm{~V}$, and desodiated clathrate at the end of the cell cycling.

\begin{tabular}{|c|c|c|c|c|c|c|}
\hline \multirow[b]{2}{*}{ Electrode Element } & \multicolumn{2}{|c|}{ Fresh electrode } & \multicolumn{2}{|c|}{$\begin{array}{l}\text { Sodiated after the } \\
\text { first discharge }\end{array}$} & \multicolumn{2}{|c|}{$\begin{array}{l}\text { Desodiated } \\
\text { after cycling }\end{array}$} \\
\hline & $\mathrm{Wt} \%$ & At. $\%$ & $\mathrm{Wt} \%$ & At. $\%$ & $\mathrm{Wt} \%$ & At. $\%$ \\
\hline O K & 9.35 & 10.61 & 9.48 & 9.60 & 17.52 & 19.12 \\
\hline $\mathrm{NaK}$ & 7.64 & 6.04 & 8.73 & 6.15 & 13.70 & 10.40 \\
\hline Si K & 47.37 & 30.63 & 32.28 & 18.63 & 33.21 & 20.65 \\
\hline
\end{tabular}

electrodes and reaches the highest after cycling, indicating more and more $\mathrm{Na}^{+}$ions are trapped in the electrode because of side reactions, leading to the clathrate deterioration and active material loss. The $\mathrm{O}$ signal can be contributed from electrolyte solvent decomposition. ${ }^{29}$ Fluorine (F) and phosphorus (P) signals are likely from the SEI and electrolyte residual.

XPS survey spectra are shown in Figure 6. Core levels for the $\mathrm{Na} 1 \mathrm{~s}, \mathrm{~F} 1 \mathrm{~s}$, and Si $2 \mathrm{p}$ are shown in Figure 7. These were compared between the fresh (uncycled) and cycled clathrate electrodes at $0 \%$ SOC (desodiated state). The cycled electrode was obtained after cell cycling at the deintercalated state. The survey spectra in Figure 6 and the core level analysis results in Table III show that the Na signal is much higher in the cycled clathrate relative to the fresh, consistent with the EDS results. The accumulation of $\mathrm{Na}^{+}$ions in the clathrate results in active material loss and becomes a significant factor in the low $\mathrm{CE}$ of

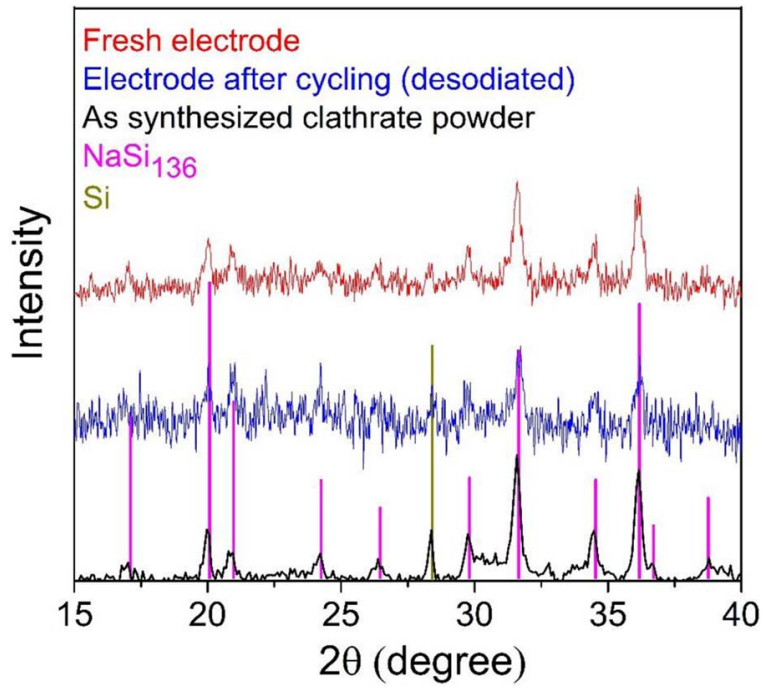

Figure 4. XRD patterns of the fresh (red), cycled clathrate anodes (blue), and as-synthesized clathrate powders (black) with the standard patterns of Si (dark yellow) and $\mathrm{NaSi}_{136}$ (magenta) reveal that there were no changes to the bulk. Any changes to the impedance was likely caused by surface limitations. the $1^{\text {st }}$ cycle and cell capacity loss during cycling. Figure 7A shows the $\mathrm{Na}$ 1s core level spectra, with peak intensity increase and peak shift to a higher energy level for the cycled clathrate. Na metal would be found near $1071.7 \mathrm{eV}^{30}$ and $\mathrm{NaF}$ found near $1071.3 \mathrm{eV} .^{31}$ The binding energy peak shift to a higher value $(1072.3 \mathrm{eV})$ after cycling is likely caused by an increased oxidative environment, indicating the side reactions and the thickening of the SEI. Figure 7B shows two new species containing $\mathrm{F}$ ( $\mathrm{F} 1 \mathrm{~s}$ peaks at $688 \mathrm{eV}$ for $\mathrm{P}-\mathrm{F}$ and $684.5 \mathrm{eV}$ for $\mathrm{Na}-\mathrm{F})$ on the surface of the cycled electrode. ${ }^{32}$ The $\mathrm{F} 1 \mathrm{~s}$ peak for the fresh electrode is from the etching residual. The $\mathrm{Si} 2 \mathrm{p}$ peak of the cycled electrode in Figure $7 \mathrm{C}$ was attenuated while the $\mathrm{Na} 1 \mathrm{~s}, \mathrm{~F} 1 \mathrm{~s}$ and $\mathrm{O} 1 \mathrm{~s}$ signals increased after cycling. The carbon black signal was strongly suppressed by a host of other C-moieties after cycling, as shown in Figure 7D. The $\mathrm{C} 1 \mathrm{~s}$ core level spectra were fitted with 7 peaks, majorly dominated by the species originated from the decompositions of organic solvents ${ }^{33-37}$ after cycling. Therefore, XPS results prove the side reactions on the surface of the cycled clathrate electrodes.

Computational analysis. $-\mathrm{Na}^{+}$transport behavior in type II $\mathrm{Si}$ clathrate was computed using the first-principles calculations with projector augmented wave (PAW) pseudopotentials, ${ }^{38,39}$ as implemented in Vienna ab initio simulation package (VASP). ${ }^{40}$ PBEsol functional was applied in the simulation. A $5 \times 5 \times 5$ k-points mesh, a planewave cutoff of $500 \mathrm{eV}$ and a force convergence tolerance of $2.5 \mathrm{meV} / \AA$ were employed in structural relaxation. Electronic configurations of PAW potentials for $\mathrm{Na}$ and $\mathrm{Si}$ are $2 s^{2} 2 p^{6} 3 s^{1}$ and $2 s^{2} 2 p^{6} 3 s^{2} 3 p^{2}$ respectively. Migration barriers of $\mathrm{Na}$ ions were calculated through Climbing Image-Nudged Elastic Band (CI-NEB) method. ${ }^{41}$

Structural relaxation of type II Si clathrate was conducted based on a cell of $136 \mathrm{Si}$ atoms, producing an equilibrium lattice constant of $14.741 \AA$. Simulations on the doping and diffusion of $\mathrm{Na}+$ were

\begin{tabular}{|c|c|c|c|c|c|}
\hline Sample & C & $\mathrm{F}$ & $\mathrm{Na}$ & $\mathrm{O}$ & $\mathrm{Si}$ \\
\hline Fresh & 71 & 2 & 0.4 & 21 & 6 \\
\hline Cycled & 34 & 10 & 23 & 31 & 2 \\
\hline
\end{tabular}
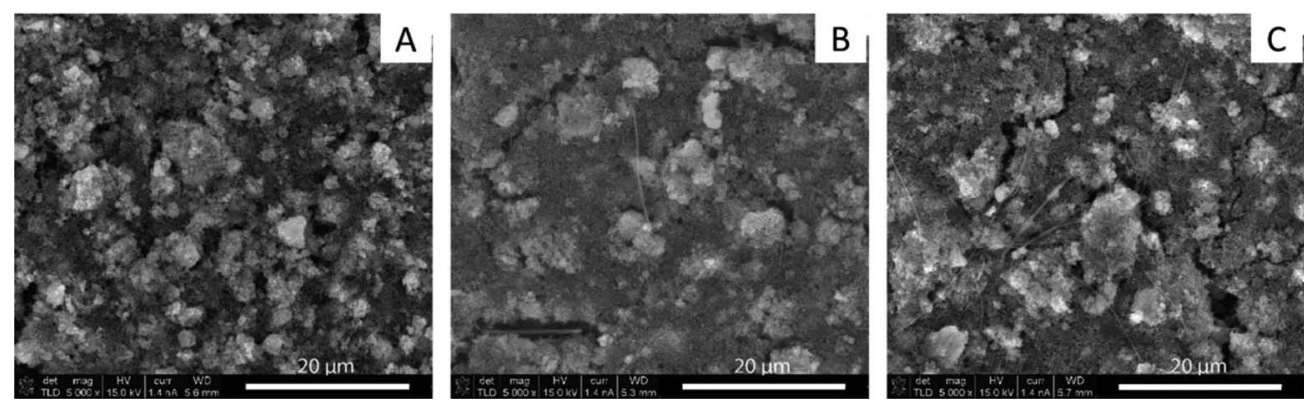

Figure 5. SEM images of the clathrate anodes at different states. (A) Fresh clathrate anode; (B) Sodiated clathrate anode after the first discharge from open circuit voltage to $0.01 \mathrm{~V}$; (C) Desodiated clathrate anode at the end of the cell cycling. 


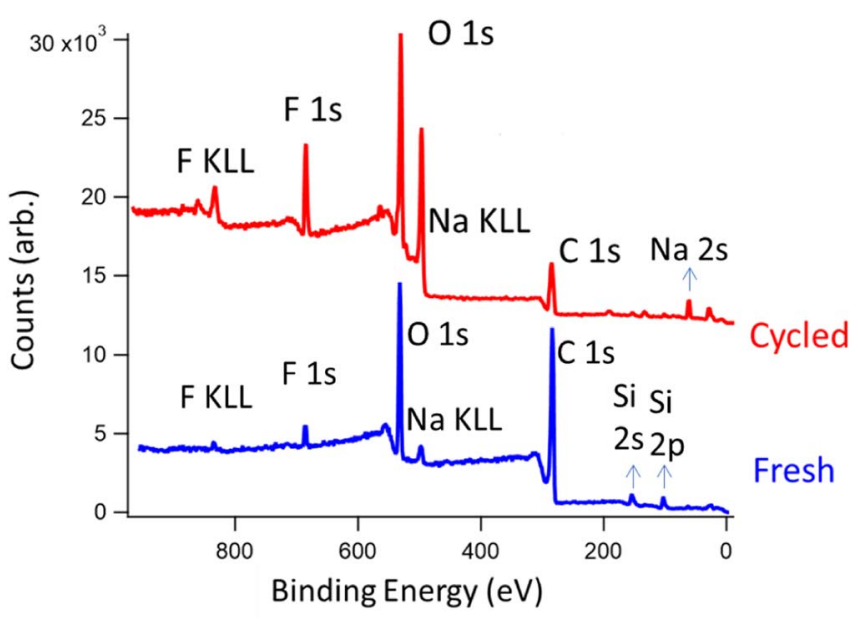

Figure 6. XPS survey spectra for fresh (blue) and cycled (red) electrodes at the desodiated state.

conducted based on a larger supercell of $272 \mathrm{Si}$ atoms. Figure $8 \mathrm{~A}$ is a scheme of type II Si clathrate atomic structure, composed of connected $\mathrm{Si}_{20}$ and $\mathrm{Si}_{28}$ cages. Na ions can diffuse among silicon cages by hopping through the shared $\mathrm{Si}_{5}$ pentagon and $\mathrm{Si}_{6}$ hexagon. The areas of $\mathrm{Si}_{5}$ pentagon and $\mathrm{Si}_{6}$ hexagon are 9.66 and $14.64 \AA^{2}$, respectively. Diffusion energy barriers of $\mathrm{Na}^{+}$ions among $\mathrm{Si}$ cages are simulated on $\mathrm{Na}_{0.5} @ \mathrm{Si}_{136}$ and $\mathrm{Na}_{24} @ \mathrm{Si}_{136}$. Lattice constant extends slightly to $14.77 \AA$ A, when type II Si clathrate reaches $\mathrm{Na}_{24} @ \mathrm{Si}_{136}$. The energy barriers are listed in Table IV and the energy changes during diffusion processes at different $\mathrm{Na}^{+}$concentrations are illustrated in Figure 9. When the concentration of $\mathrm{Na}^{+}$is low $\left(\mathrm{Na}_{0.5} @ \mathrm{Si}_{136}\right)$, diffusion between $\mathrm{Si}$ cages has energy barriers over $2 \mathrm{eV}$, indicating slow ionic transport. In $\mathrm{Na}_{0.5} @ \mathrm{Si}_{136}$, the $\mathrm{Si}_{28}$ cage is the energetically favorable site for $\mathrm{Na}^{+}$, which is ascribed to the larger area of the $\mathrm{Si}_{6}$ hexagon, and therefore $\mathrm{Na}^{+}$ions are more likely transported through a tunnel made of $\mathrm{Si}_{28}$ cages during the charging/discharging (desodiation/sodiation) processes. However, when $\mathrm{Na}^{+}$doping reaches $\mathrm{Na}_{24} @ \mathrm{Si}_{136}$, all $\mathrm{Si}_{20}$ and $\mathrm{Si}_{28}$ cages are occupied. Two $\mathrm{Na}^{+}$ions occupy one $\mathrm{Si}_{28}$ cage when concentration of $\mathrm{Na}^{+}$is higher than $\mathrm{Na}_{24} @ \mathrm{Si}_{136}$. Ionic transport of $\mathrm{Na}+$ under high $\mathrm{Na}+$ concentration mainly involves diffusion between fully occupied $\mathrm{Si}_{28}$ cage $\left(\mathrm{Na}_{2} @ \mathrm{Si}_{28}\right)$ and half occupied $\mathrm{Si}_{28}$ cages $\left(\mathrm{Na}_{1} @ \mathrm{Si}_{28}\right)$. Diffusion energy barriers of $\mathrm{Na}_{24} @ \mathrm{Si}_{136}$ are relatively lower than those of $\mathrm{Na}_{0.5} \mathrm{Si}_{136}$, indicating that the ionic transport kinetics is enhanced by doping of $\mathrm{Na}^{+}$. The lowest diffusion energy barrier is $1.07 \mathrm{eV}$ around the stoichiometric formula of $\mathrm{Na}_{24} \mathrm{Si}_{136}$ (diffusion from half occupied $\mathrm{Si}_{28}$ cage to a nearby empty $\mathrm{Si}_{20}$ cage), which is similar to the result from layered $\mathrm{Si}^{3}$ Even though diffusion
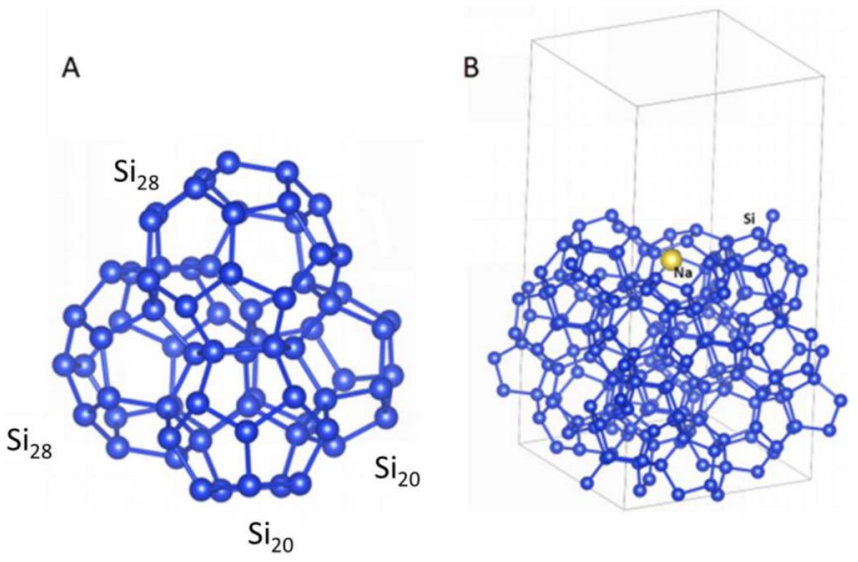

Figure 8. (A) Atomic structure of Type II Si clathrate composed of connected $\mathrm{Si}_{20}$ and $\mathrm{Si}_{28}$ cages; (B) An example of $\mathrm{Na}^{+}$adsorption site on the surface of type II Si clathrate.

is very hard for Si-clathrate at low concentration of $\mathrm{Na}^{+}$, doping can accelerate diffusion and make ionic transport comparable with other materials when a critical $\mathrm{Na}^{+}$concentration is achieved. The computational finding is consistent with our experimental EIS analysis: during the initial $\mathrm{Na}^{+}$insertion from OCV to $0.01 \mathrm{~V}$, the charge transfer resistance decreases with decreasing cell voltage.

In addition, various surface configurations were simulated. We found that the surface adsorption energy is $0.04 \sim 0.21 \mathrm{eV}$ lower than doping within $\mathrm{Si}_{20}$ and $\mathrm{Si}_{28}$ cages, depending on surface configurations and concentration of $\mathrm{Na}^{+}$ions. One adsorption site on the (100) surface of type II Si clathrate is shown in Figure 8B, which is surrounded by two $\mathrm{Si}_{28}$ and six $\mathrm{Si}_{20}$ cages. This surface adsorption energy is $0.18 \mathrm{eV}$ lower than in the $\mathrm{Si}_{28}$ structure. When the concentration of $\mathrm{Na}^{+}$ions is low, $\mathrm{Na}^{+}$ions are more likely trapped on the surface of type II silicon clathrate. As concentration of $\mathrm{Na}^{+}$ion increases, more surface adsorption sites are occupied, and $\mathrm{Na}$ ions diffuse into type II $\mathrm{Si}$ clathrate through the diffusion path of $\mathrm{Si}_{28}$ cages. Therefore, it is predicted that a considerable amount of $\mathrm{Na}^{+}$is trapped on the surface of type II Si clathrate, which eventually leads to the side products and SEI layer formation.

Based on the above computational results and analysis, the impact of testing temperature on the battery performance can be explained as follows. Due to the different diffusion energy barriers from cages to cages, at moderate temperature, $\mathrm{Na}^{+}$ions are most likely transported along the tunnel of $\mathrm{Si}_{28}$ cages. $\mathrm{Si}_{20}$ cages may trap $\mathrm{Na}^{+}$ions unless the temperature is elevated to overcome the diffusion energy barrier from $\mathrm{Si}_{20}$ to $\mathrm{Si}_{20}$. Another reason for the improved battery
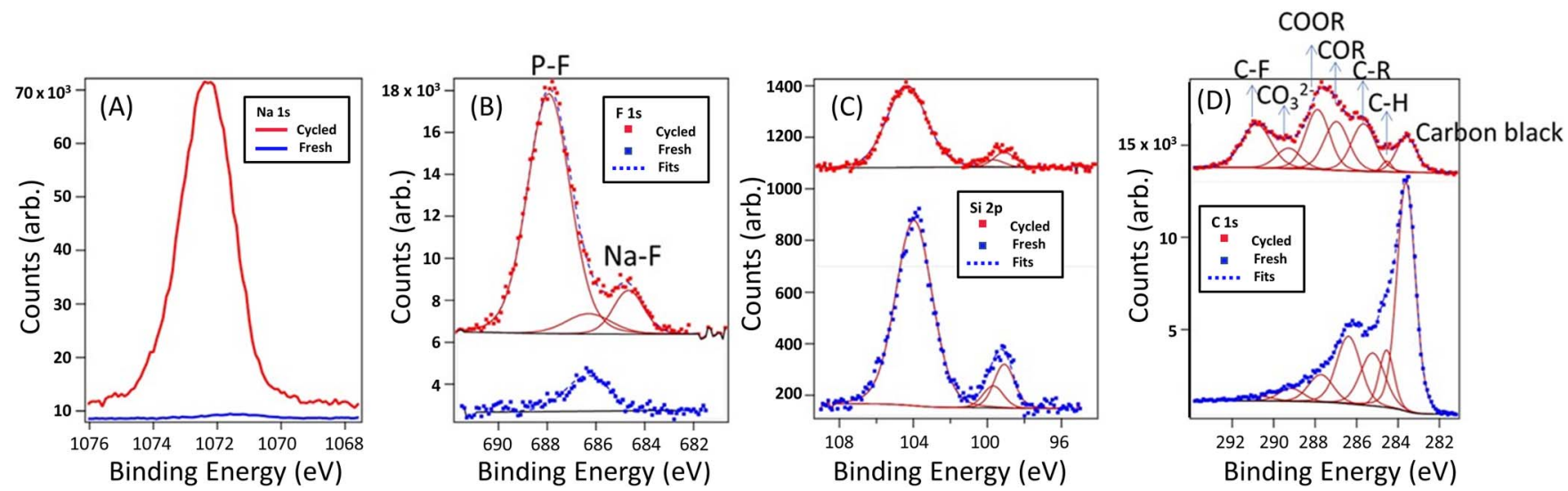

Figure 7. Comparison of Na 1s (A), F 1s (B), Si 2p (C), and C 1s (D) core level spectra for the fresh and cycled electrodes at the desodiated state reveals (See Table II) preferential accumulation of sodium on the surface of the particles, consistent with the EDS results shown in Table II. 
Table IV. Diffusion energy barriers of $\mathrm{Na}^{+}$between different $\mathrm{Si}$ cages.

Starting structure

Final structure

$\mathrm{Na}^{+}$concentration

Diffusion energy barrier (eV)

$\mathrm{Na}_{2} @ \mathrm{Si}_{28}+\mathrm{Na}_{0} @ \mathrm{Si}_{28}$

$\mathrm{Na}_{2} @ \mathrm{Si}_{28}+\mathrm{Na}_{1} @ \mathrm{Si}_{28}$

$\mathrm{Na}_{1} @ \mathrm{Si}_{28}+\mathrm{Na}_{0} @ \mathrm{Si}_{28}$

$\mathrm{Na}_{1} @ \mathrm{Si}_{28}+\mathrm{Na}_{0} @ \mathrm{Si}_{20}$

$\mathrm{Na}_{1} @ \mathrm{Si}_{28}+\mathrm{Na}_{0} @ \mathrm{Si}_{20}$

$\mathrm{Na}_{1} @ \mathrm{Si}_{20}+\mathrm{Na}_{0} @ \mathrm{Si}_{20}$

$\mathrm{Na}_{1} @ \mathrm{Si}_{28}+\mathrm{Na}_{0} @ \mathrm{Si}_{28}$
$\mathrm{Na}_{1} @ \mathrm{Si}_{28}+\mathrm{Na}_{1} @ \mathrm{Si}_{28}$
$\mathrm{Na}_{1} @ \mathrm{Si}_{28}+\mathrm{Na}_{2} @ \mathrm{Si}_{28}$
$\mathrm{Na}_{0} @ \mathrm{Si}_{28}+\mathrm{Na}_{1} @ \mathrm{Si}_{28}$
$\mathrm{Na}_{0} @ \mathrm{Si}_{28}+\mathrm{Na}_{1} @ \mathrm{Si}_{20}$
$\mathrm{Na}_{0} @ \mathrm{Si}_{28}+\mathrm{Na}_{1} @ \mathrm{Si}_{20}$
$\mathrm{Na}_{0} @ \mathrm{Si}_{20}+\mathrm{Na}_{1} @ \mathrm{Si}_{20}$
$\mathrm{Na}_{0} @ \mathrm{Si}_{28}+\mathrm{Na}_{1} @ \mathrm{Si}_{28}$

performance at elevated temperature is that higher mobility of $\mathrm{Na}^{+}$on the surface makes it easy to migrate into the $\mathrm{Si}_{28}$ cages. Therefore, the cell Coulombic efficiency, specific capacity and rate performance are improved at $45^{\circ} \mathrm{C}$ compared with room temperature, as observed in the experiment.

\section{Conclusions}

This study presents our initial results on clathrate anodes for SIBs and will be helpful for SIB anode development. The as-synthesized type II clathrates in SIBs shows both promises and challenges. The stable cycling capacity is ascribed to small volume changes during $\mathrm{Na}^{+}$ insertion and extraction. Elevating the cell temperature can improve the cell capacity and cycling stability. However, the challenges are the low CE of the first cycle because of side reactions on the surfaces and low ionic diffusion rates. Possible ways to improve the clathrate

$\begin{array}{ll}\mathrm{Na}_{24} @ \mathrm{Si}_{136} & 1.54 \\ \mathrm{Na}_{24.5} @ \mathrm{Si}_{136} & 1.63 \\ \mathrm{Na}_{23.5} @ \mathrm{Si}_{136} & 2.26 \\ \mathrm{Na}_{23.5} @ \mathrm{Si}_{136} & 1.07 \\ \mathrm{Na}_{0.5} @ \mathrm{Si}_{136} & 2.47 \\ \mathrm{Na}_{0.5} @ \mathrm{Si}_{136} & 2.65 \\ \mathrm{Na}_{0.5} @ \mathrm{Si}_{136} & 2.12\end{array}$

performance may include controlling the stoichiometric formula and morphology of the starting clathrate materials. Additionally, removing the Si impurity is helpful to improve the cell CE. Considering its electrochemical properties, a type II clathrate anode has potential to be employed in SIBs that have more stringent requirements for battery life compared with energy density.

\section{Acknowledgments}

This work was authored in part by the National Renewable Energy Laboratory, operated by Alliance for Sustainable Energy, LLC, for the U.S. Department of Energy (DOE) under Contract No. DE-AC36-08GO28308. Funding was provided by the National Renewable Energy Laboratory's Laboratory Directed Research and Development Program. Support for the synthesis of clathrates by Lakshmi Krishna was provided by Energy Frontier Research in Extreme
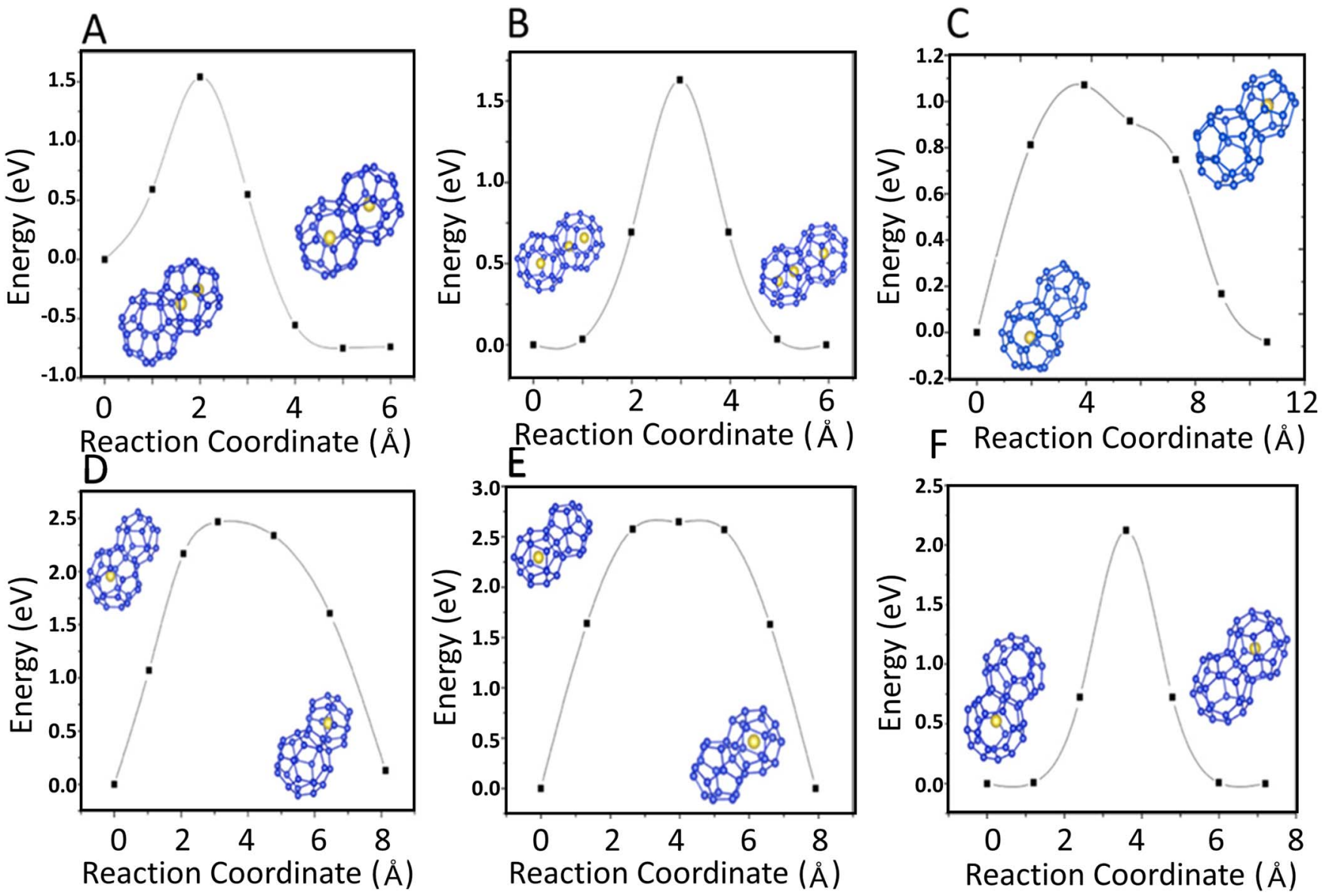

Figure 9. Diffusion energy barriers of $\mathrm{Na}^{+}$between (A) a fully occupied $\mathrm{Si}_{28}$ cage and an empty $\mathrm{Si}_{28}$ cage in $\mathrm{Na}_{24} \mathrm{Si}_{136}$, (B) a fully occupied $\mathrm{Si}_{28}$ cage and a half occupied $\mathrm{Si}_{28}$ cage in $\mathrm{Na}_{24.5} \mathrm{Si}_{136}$, (C) a half occupied $\mathrm{Si}_{28}$ cage and an empty $\mathrm{Si}_{20}$ cage in $\mathrm{Na}_{23.5} \mathrm{Si}_{136}$, (D) a half occupied $\mathrm{Si}_{28}$ cage and an empty $\mathrm{Si}_{20}$ cage in $\mathrm{Na}_{0.5} \mathrm{Si}_{136}$, (E) an occupied $\mathrm{Si}_{20}$ cage and an empty $\mathrm{Si}_{20}$ cage in $\mathrm{Na}_{0.5} \mathrm{Si}_{136},(\mathrm{~F})$ a half occupied $\mathrm{Si}_{28}$ cage and an empty $\mathrm{Si}_{28}$ cage in $\mathrm{Na}_{0.5} \mathrm{Si}_{136}$. 
Environments (EFree) Center, an Energy Frontier Research Center funded by the US Department of Energy, Office of Science under award No. DE-SC0001057. The views expressed in the article do not necessarily represent the views of the DOE or the U.S. Government. The U.S. Government retains and the publisher, by accepting the article for publication, acknowledges that the U.S. Government retains a nonexclusive, paid-up, irrevocable, worldwide license to publish or reproduce the published form of this work, or allow others to do so, for U.S. Government purposes.

\section{ORCID}

Kae Fink (10 https://orcid.org/0000-0001-9363-4632

Shriram Santhanagopalan (1) https://orcid.org/0000-0003-4703-1341

\section{References}

1. V. Palomares, P. Serras, I. Villaluenga, K. B. Hueso, J. Carretero-Gonzalez, and T. Rojo, Energy \& Environmental Science, 5, 5884 (2012).

2. T. Georgi-Maschler, B. Friedrich, R. Weyhe, H. Heegn, and M. Rutz, Journal of Power Sources, 207, 173 (2012).

3. C. Bommier and X. Ji, Israel Journal of Chemistry, 55, 486 (2015).

4. W. Luo, F. Shen, C. Bommier, H. Zhu, X. Ji, and L. Hu, Accounts of Chemical Research, 49, 231 (2016).

5. K. Chayambuka, G. Mulder, D. L. Danilov, and P. H. L. Notten, Advanced Energy Materials, 8, 1800079 (2018).

6. D. Y. Kim, S. Stefanoski, O. O. Kurakevych, and T. A. Strobel, Nature Materials, 14 $169(2014)$

7. X. Li, F. E. Kersey-Bronec, J. Ke, J. E. Cloud, Y. Wang, C. Ngo, S. Pylypenko, and Y. Yang, ACS Applied Materials \& Interfaces, 9, 16071 (2017).

8. M. Ashuri, Q. He, and L. L. Shaw, Nanoscale, 8, 74 (2016).

9. U. Arrieta, N. A. Katcho, O. Arcelus, and J. Carrasco, Scientific Reports, 7, 5350 (2017).

10. P. Warrier and C. A. Koh, Applied Physics Reviews, 3, 040805 (2016).

11. N. A. Wagner, R. Raghavan, R. Zhao, Q. Wei, X. Peng, and K. Chan Candace, ChemElectroChem, 1, 347 (2013).

12. J. G. Slingsby, N. A. Rorrer, L. Krishna, E. S. Toberer, C. A. Koh, and C. M. Maupin, Physical Chemistry Chemical Physics, 18, 5121 (2016).

13. R. Zhao, S. Bobev, L. Krishna, T. Yang, J. M. Weller, H. Jing, and C. K. Chan, ACS Applied Materials \& Interfaces, 9, 41246 (2017).

14. K. S. Chan, M. A. Miller, C. Ellis-Terrell, and C. K. Chan, MRS Advances, 1, 3043 (2016).

15. T. Langer, S. Dupke, H. Trill, S. Passerini, H. Eckert, R. Pöttgen, and M. Winter, Journal of The Electrochemical Society, 159, A1318 (2012).
16. Y. Li, R. Raghavan, N. A. Wagner, S. K. Davidowski, L. Baggetto, R. Zhao, Q. Cheng, J. L. Yarger, G. M. Veith, C. Ellis-Terrell, M. A. Miller, K. S. Chan, and C. K. Chan, Advanced Science, 2, 1500057 (2015).

17. K. S. Chan, M. A. Miller, W. Liang, C. Ellis-Terrell, and C. K. Chan, Journal of Materials Research, 32, 2628 (2017).

18. X. Peng, Q. Wei, Y. Li, and C. K. Chan, The Journal of Physical Chemistry C, 119, 28247 (2015).

19. J. Yang and J. S. Tse, Journal of Materials Chemistry A, 1, 7782 (2013).

20. Y. Li, R. Raghavan, N. A. Wagner, S. K. Davidowski, L. Baggetto, R. Zhao, Q. Cheng, J. L. Yarger, G. M. Veith, C. Ellis-Terrell , M. A. Miller , K. S. Chan , and C. K. Chan, Advanced Science, 2, 1500057 (2015).

21. Y. He, X. Lu, and D. Y. Kim, RSC Advances, 8, 20228 (2018).

22. A. Marzouk, P. B. Balbuena, and F. El-Mellouhi, Electrochimica Acta, 207, 301 (2016).

23. L. Krishna, L. L. Baranowski, A. D. Martinez, C. A. Koh, P. C. Taylor, A. C. Tamboli, and E. S. Toberer, CrystEngComm, 16, 3940 (2014).

24. M. Klett, J. A. Gilbert, S. E. Trask, B. J. Polzin, A. N. Jansen, D. W. Dees, and D. P. Abraham, Journal of The Electrochemical Society, 163, A875 (2016).

25. M. D. Levi and D. Aurbach, The Journal of Physical Chemistry B, 108, 11693 (2004).

26. M. D. Levi and D. Aurbach, Journal of Power Sources, 146, 727 (2005).

27. M. D. Murbach and D. T. Schwartz, Journal of The Electrochemical Society, 165, A297 (2018).

28. E. Markevich, G. Salitra, and D. Aurbach, ACS Energy Letters, 2, 1337 (2017).

29. S. Xia, L. Mu, Z. Xu, J. Wang, C. Wei, L. Liu, P. Pianetta, K. Zhao, X. Yu, F. Lin, and Y. Liu, Nano Energy, 53, 753 (2018).

30. S. P. Kowalczyk, L. Ley, F. R. McFeely, R. A. Pollak, and D. A. Shirley, Physical Review B, 8, 3583 (1973).

31. V. I. Nefedov, Y. V. Salyn, G. Leonhardt, and R. Scheibe, Journal of Electron Spectroscopy and Related Phenomena, 10, 121 (1977).

32. Z. W. Seh, J. Sun, Y. Sun, and Y. Cui, ACS Central Science, 1, 449 (2015).

33. Q. Ma, B. Tong, Z. Fang, X. Qi, W. Feng, J. Nie, Y.-S. Hu, H. Li, X. Huang, and L. Chen, Journal of The Electrochemical Society, 163, A1776 (2016).

34. M. Nie, D. P. Abraham, Y. Chen, A. Bose, and B. L. Lucht, The Journal of Physical Chemistry C, 117, 13403 (2013).

35. T. Dong, J. Zhang, G. Xu, J. Chai, H. Du, L. Wang, H. Wen, X. Zang, A. Du, Q. Jia, X. Zhou, and G. Cui, Energy \& Environmental Science, 11, 1197 (2018).

36. N.-W. Li, Y. Shi, Y.-X. Yin, X.-X. Zeng, J.-Y. Li, C.-J. Li, L.-J. Wan, R. Wen, and Y.-G. Guo, Angewandte Chemie International Edition, 57, 1505 (2018).

37. B. S. Parimalam, A. D. MacIntosh, R. Kadam, and B. L. Lucht, The Journal of Physical Chemistry C, 121, 22733 (2017).

38. P. E. Blöchl, Physical Review B, 50, 17953 (1994).

39. G. Kresse and D. Joubert, Physical Review B, 59, 1758 (1999).

40. G. Kresse and J. Furthmüller, Physical Review B, 54, 11169 (1996).

41. G. Henkelman, B. P. Uberuaga, and H. Jónsson, The Journal of Chemical Physics, 113, 9901 (2000).

42. V. V. Kulish, O. I. Malyi, M.-F. Ng, Z. Chen, S. Manzhos, and P. Wu, Physical Chemistry Chemical Physics, 16, 4260 (2014). 